\title{
EUS-guided hepaticoduodenostomy combined with antegrade metal stenting using an ultrathin flexible delivery system
}

EUS-guided hepaticogastrostomy (HGS) combined with antegrade metal stenting (AS) can achieve longer stent patency and may be associated with fewer procedure-related adverse events (AEs) compared to EUS-HGS or EUS-AS alone [13]. However, EUS-guided hepaticoduodenostomy (HDS) with AS remains challenging [4]. Because the angle between the right hepatic bile duct and inserted device is typically extremely acute, antegrade insertion of hard and thick devices, such as a metal stent, is often extremely challenging. Here, we report a successful case of EUS-HDS with AS using a metal stent with 5.4-Fr ultra-thin flexible delivery system and a dedicated plastic stent.

An 84-year-old woman with a history of left lobectomy for liver metastasis of colonic cancer developed jaundice as a result of distal biliary obstruction owing to recurrence ( $\mathbf{F i g . 1}$ ). Because endoscopic retrograde cholangiopancreatography (ERCP) had failed, owing to duodenal invasion, EUS-guided drainage was attempted. The right intrahepatic bile duct was punctured using a 19gauge needle, and a 0.025 -inch guidewire was inserted into the bile duct, followed by a tapered catheter. Subsequently, the guidewire traversed the stricture and advanced into the duodenum, and the fistula was dilated using a 4-mm balloon catheter (Kaneka Medix, Osaka, Japan). A novel metal stent with a 5.4-Fr delivery system $(8 \times 80 \mathrm{~mm}$; Zeo Stent V; Zeon Medical, Tokyo, Japan), which is commercially available in Japan, was subsequently inserted and placed antegrade across the stricture. Finally, a 7-Fr dedicated single-pigtail plastic stent (Gadelius Medical, Tokyo, Japan), originally designed for EUS-HGS [5], was placed from the hepatic duct to the stomach ( $\triangleright$ Fig. 2 and $\triangleright$ Video 1 ). The obstructive jaundice improved postoperatively, without any AEs.
The ultrathin flexible metal stent delivery system may facilitate AS through EUSHDS. This procedure may be a useful option for treating malignant biliary obstruction in patients with failed ERCP who require an approach via the right intrahepatic bile duct.
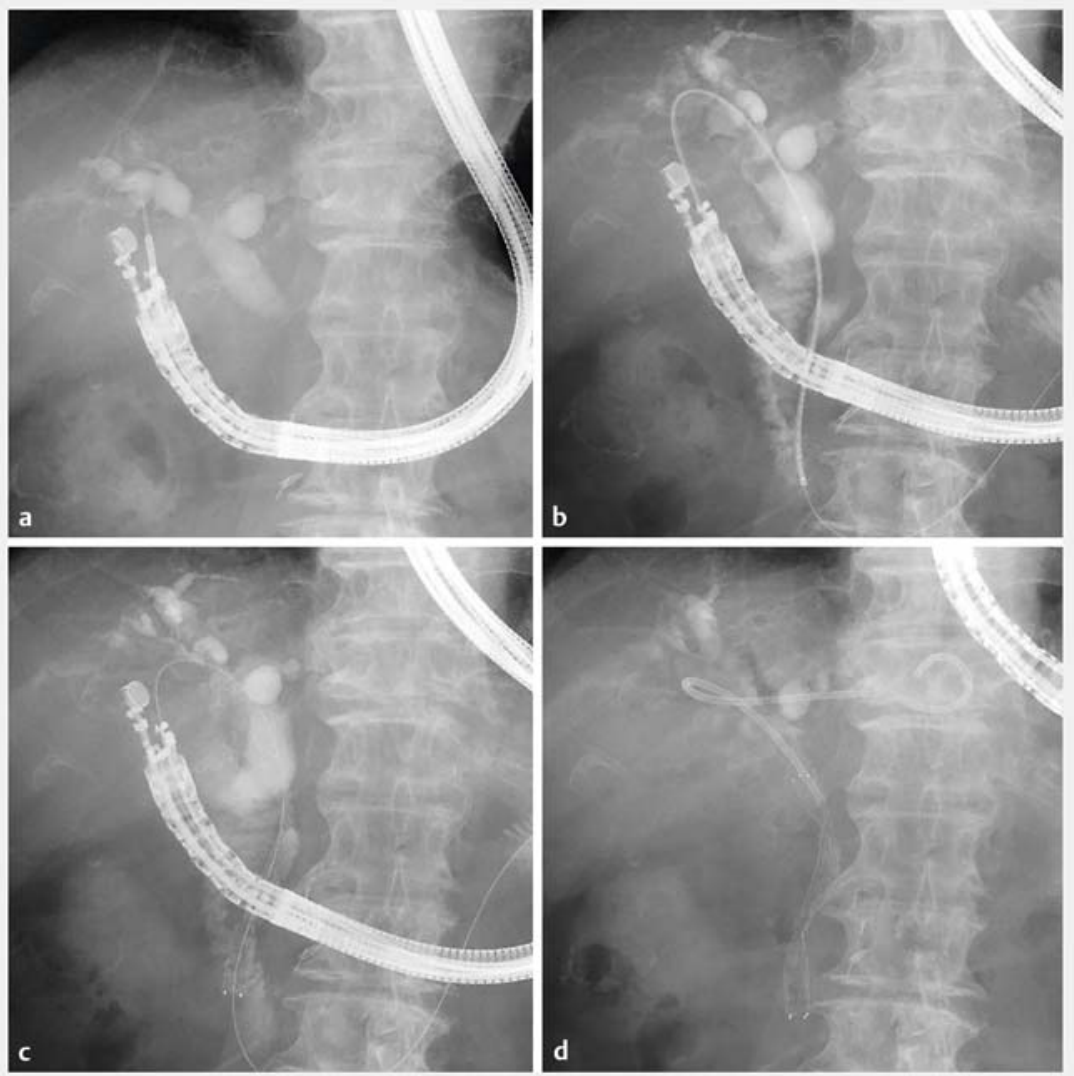

- Fig. 2 a The angle between the right hepatic bile duct and puncture route was extremely acute. b A 5.4-Fr ultrathin flexible delivery system was inserted into the bile duct. c The metal stent was placed antegrade across the bile duct stricture. $\mathbf{d}$ A dedicated single-pigtail stent was placed from the hepatic duct to the stomach. 


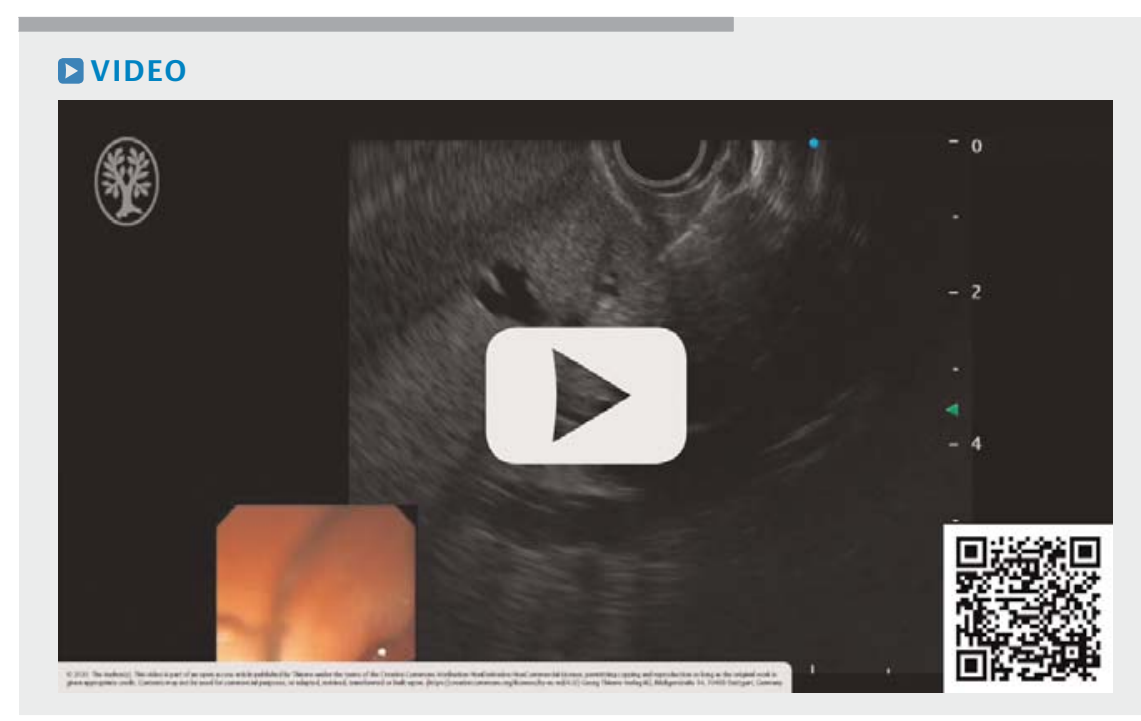

- Video 1 EUS-guided hepaticoduodenostomy with antegrade metal stenting using a metal stent with 5.4-Fr ultra-thin flexible delivery system and a dedicated plastic stent.

\section{Competing interests}

The authors declare that they have no conflict of interest.

The authors

Tadahisa Inoue, Mayu Ibusuki, Rena Kitano, Yuji Kobayashi, Kiyoaki Ito, Masashi Yoneda Department of Gastroenterology, Aichi Medical University, 1-1 Yazakokarimata, Nagakute, Aichi 480-1195, Japan

\section{References}

[1] Mukai S, Itoi T. EUS-guided antegrade procedures. Endosc Ultrasound 2019; 8: S7S13

[2] Ogura T, Kitano M, Takenaka M et al. Multicenter prospective evaluation study of endoscopic ultrasound-guided hepaticogastrostomy combined with antegrade stenting (with video). Dig Endosc 2018; 30: 252-259

[3] Yamamoto K, Itoi T, Tsuchiya T et al. EUSguided antegrade metal stenting with hepaticoenterostomy using a dedicated plastic stent with a review of the literature (with video). Endosc Ultrasound 2018; 7: 404-412

[4] Park SJ, Choi JH, Park DH et al. Expanding indication: EUS-guided hepaticoduodenostomy for isolated right intrahepatic duct obstruction (with video). Gastrointest Endosc 2013; 78: 374-380

[5] Umeda J, Itoi T, Tsuchiya T et al. A newly designed plastic stent for EUS-guided hepaticogastrostomy: a prospective preliminary feasibility study (with videos). Gastrointest Endosc 2015; 82: 390-396

\section{Bibliography}

Endoscopy International Open 2021; 09: E417-

E418

DOI 10.1055/a-1326-1611

ISSN 2364-3722

(c) 2021. The Author(s).

This is an open access article published by Thieme under the terms of the Creative Commons Attribution-NonDerivativeNonCommercial License, permitting copying and reproduction so long as the original work is given appropriate credit. Contents may not be used for commecial purposes, or adapted, remixed, transformed or built upon. (https:// creativecommons.org/licenses/by-nc-nd/4.0/)

Georg Thieme Verlag KG, Rüdigerstraße 14, 70469 Stuttgart, Germany

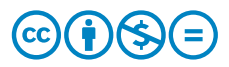

